\title{
Devitrification in Annealed Optical Fiber
}

\author{
A. H. Rose
}

\begin{abstract}
The decrease in transmittance of annealed optical fiber has been measured versus temperature and time. The annealing loss is due to the devitrification of the glass and $\mathrm{OH}$ absorption in the 1200 to $1500 \mathrm{~nm}$ wavelength region. Both loss mechanisms propagate primarily from the surface into the core. However, to increase the $\mathrm{OH}$ absorption significantly, annealing times greater than $10 \mathrm{~h}$ are required. Fibers heated from 1000 to $1300{ }^{\circ} \mathrm{C}$ in an air atmosphere quickly devitrify and their transmittance approaches zero. Also, the current sensitivity of annealed fiber current sensors versus annealing time at $850{ }^{\circ} \mathrm{C}$ has been measured. A decrease in the current sensitivity is attributed to devitrification in the fiber.
\end{abstract}

\section{INTRODUCTION}

$\mathbf{I}$ $\mathrm{N}$ this paper, the effects of devitrification in annealed optical fibers are briefly discussed. Thermally processing optical fiber produces many useful components: splices, couplers, thermally expanded core fiber, fiber lenses, chirped Bragg gratings, and sensors that measure current, voltage, temperature, and strain [1]-[6]. However, the heat treatment can, under certain conditions, devitrify the glass fiber, i.e., nucleate and grow crystals within the glass matrix [7]-[10].

Devitrification in silica glass can occur through a nucleation and growth process at temperatures between about 200 and $800{ }^{\circ} \mathrm{C}$, depending on the glass composition [11]. (Typical optical fiber with 4 mole $\%$ of $\mathrm{GeO}_{2}$ in $\mathrm{SiO}_{2}$, may have a higher nucleation temperature.) Crystal growth proceeds from the nuclei present for temperatures near $800{ }^{\circ} \mathrm{C}$ to a few hundred degrees Celsius below the melting point, which is about $1800{ }^{\circ} \mathrm{C}$ in fibers [11]-[13]. If the temperature of the glass remains low, nucleation will occur at a negligible rate because the nucleation and crystallization rates are exponential functions of temperature [10], [14]. However, further thermal processing into the crystal growth temperature range will promote growth of nuclei [8]-[14]. The phase cristobalite is the normal product of devitrification in silica glass [8], [13].

There are several ways to reduce devitrification in thermally processed fibers. One method is to rapidly heat and cool the fiber through the nucleation temperatures, minimizing the time to nucleate crystallization sites. Another is to heat the fiber near melting and cool rapidly. However, both of these methods produce thermally induced stress in the glass and, if the glass is cooled rapidly enough, a quenched state. Additives can inhibit (for example gallium oxide in borosilicate glass) or promote (for example titanium dioxide in alumina-silicate glass) crystal growth [10], [11], [15]. Devitrification can start at the glass-air

Manuscript received September 10, 1996; revised January 15, 1997. This work was supported in part by the Los Alamos National Laboratory.

The author is with the National Institute of Standards and Technology, Boulder, CO 80303 USA.

Publisher Item Identifier S 0733-8724(97)03545-7. surface and proceed inward. This can be due to the presence of surface flaws or to chemical reaction [8], [10], [16], [17]. Argon can be used to suppress surface reactions with oxygen, nitrogen, carbon dioxide, and water [1], [8], [16], [18], [19].

To produce fiber coils suitable for current sensing, all stressinduced birefringence must be removed. Coils annealed at $850^{\circ} \mathrm{C}$ will be nearly isotropic, but require a slow cooling rate, approximately $0.2^{\circ} \mathrm{C} / \mathrm{min}$ [4]. The heating rate used is limited to about $5^{\circ} \mathrm{C} / \mathrm{min}$. These rates are slow enough to allow a significant amount of nucleation to occur during the annealing cycle. The maximum temperature, $850{ }^{\circ} \mathrm{C}$, is high enough to promote crystal growth and slowly devitrify the fiber. Also, the fiber annealing is done in an atmosphere of ambient air where water, oxygen, carbon dioxide, and nitrogen can react with the glass surface to promote crystal growth [8], [11], [15], [16]. However, at this temperature the crystal growth rate is slow, and annealing times of several hours can be used without significantly affecting the performance of a current sensor [4], [8], [10], [20]-[22].

\section{EXPERIMENTAL MEASUREMENTS OF ANNEALED OPTICAL FIBER}

\section{A. Optical Fiber Current Sensors}

1) Current Sensitivity: With advances in optical fiber annealing, current sensors with nearly zero linear birefringence (nearly perfect current response) can be made [23], [24]. This advance in annealing allows a systematic look at the current sensitivity of a given fiber versus annealing time. Fig. 1 shows the current sensitivity of coils, 50.9 turns on a diameter of $7 \mathrm{~cm}$, versus the annealing time at $850{ }^{\circ} \mathrm{C}$. The fiber used was single mode at $1300 \mathrm{~nm}, 125 \mu \mathrm{m}$ diameter, step index fiber with a numerical aperture of 0.13 . The fiber cladding is $\mathrm{SiO}_{2}$ and the nominally $8 \mu \mathrm{m}$ core is about 4 mole $\%$ doped $\mathrm{GeO}_{2}: \mathrm{SiO}_{2}$ glass. The fiber jacket is treated with acetone for a few minutes before the annealing and is burned off [4]. Annealing takes about four days. Current sensitivity is measured polarimetrically using a difference-over-sum method [4]. With a known current, the sensitivity is compared to theory to obtain a relative sensitivity [4]. Fig. 1 shows that as the annealing time increases the current sensitivity decreases linearly at a rate of about $0.02 \% / \mathrm{h}$. This decrease in current sensitivity can be due to several effects individually or in combination: a depolarization of the light in the fiber, a change in the dispersion $(d n / d \lambda)$ of the fiber, or an increase in the average linear birefringence.

The primary effect causing the sensitivity change seems to be scattering from crystal sites. Scattering would depolarize the light (or lower the degree of polarization) in the fiber 


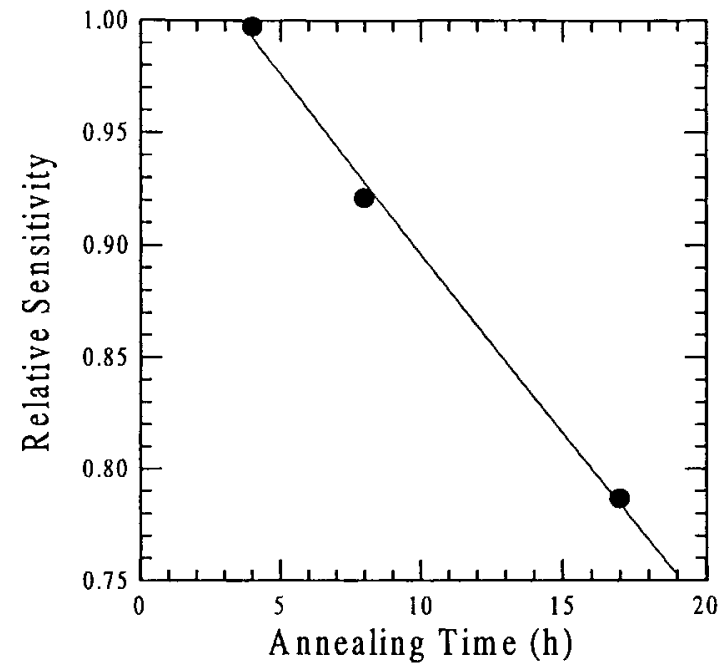

Fig. 1. Relative sensitivity of 50.9 turn, $7 \mathrm{~cm}$ diameter coils annealed at $850{ }^{\circ} \mathrm{C}$ for 4,8 , and $17 \mathrm{~h}$.

and reduce the measurable effect of the Faraday rotation [25]. The degree of polarization was measure for the coils shown in Fig. 1 and the degree of polarization change, about 25\%, would account for the change in sensitivity. Also, as discussed later, these annealed fibers have a significant amount of light scattered from the core.

The magnitude of the Faraday effect could be changed if $d n / d \lambda$ of the fiber in the $1300 \mathrm{~nm}$ wavelength region changed due to $\mathrm{OH}$ absorption [26]. In diamagnetic materials the magnitude of the Faraday effect is directly proportional to the glass dispersion. A $20 \%$ change in the dispersion would correspond to the change in current sensitivity seen in Fig. 1. However, for these modest annealing times the $\mathrm{OH}$ absorption does not increase enough to change the current sensitivity through $d n / d \lambda$. On the other hand, $\mathrm{OH}$ absorption does play a role in the loss of these annealed fiber coils.

Residual linear birefringence in the annealed fiber will reduce the measured Faraday rotation [4], [24], [25]. There are only two mechanisms to increase the linear birefringence in annealed fiber: deformation of the core and cladding [27], [28], and possibly devitrification. (Stress-induced birefringence and micro-bending birefringence is removed during anneal.) The core of the fiber waveguide will deform at high temperatures, above $1200{ }^{\circ} \mathrm{C}$, producing birefringence [27]. At $850{ }^{\circ} \mathrm{C}$ the fiber will not deform in this way, because the fiber viscosity is high enough to hold the fiber's shape. Also, the measured birefringence of these coils does not increase with annealing time. Devitrification could increase the average linear birefringence of the fiber as the glass becomes polycrystalline. When the glass is cooled the index difference between the vitreous glass state and the micro-crystals present will produce a birefringence. The orientation of the birefringence axis will vary from crystal site to crystal site; however, with enough crystal growth the average birefringence could rise to affect the fiber coil's sensitivity. This distribution of birefringence, if present, could be measured with polarization mode dispersion (PMD) techniques [29]. I have measured the PMD of a coil, about $20 \mathrm{~m}$ long, annealed for over $100 \mathrm{~h}$ at $906{ }^{\circ} \mathrm{C}$. No

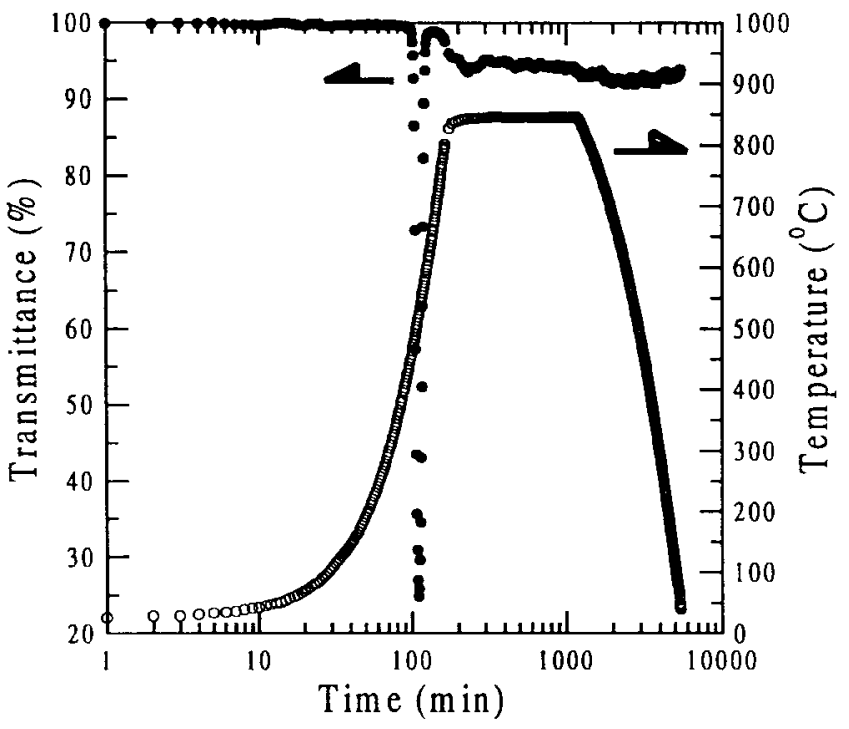

Fig. 2. The transmittance and thermal history of a 100.9 turn coil annealed at $850{ }^{\circ} \mathrm{C}$ for $17 \mathrm{~h}$. The o's mark the temperature and the $\bullet$ 's mark the transmittance.

significant PMD increase could be measured in this annealed fiber coil. From this measurement, residual birefringence, possibly due to devitrification, does not appear to be the mechanism for reduced current sensitivity in these sensors.

2. Optical Loss: Devitrification in glass fiber can increase the optical loss of a coil when light is scattered from crystal sites [10]. Additional loss in Nd-doped fiber, bulk glass, and fluoride fiber has been attributed to devitrification or scattering from crystal sites [30]-[33]. Also, loss can come from $\mathrm{OH}$ absorption and possibly micro-bending or stressinduced waveguide loss. In some cases the loss in the fiber may be due to a combination of these effects. However, in the case of stress-induced loss or microbending, the waveguide is not severely deformed, all stress is removed from the glass during annealing, and the polycrystalline structures on the surface of the glass are small.

To measure the change in loss, the optical throughput was monitored as a coil was annealed. Fig. 2 shows a plot of the transmittance at $1287 \mathrm{~nm}$ for a 100.9 turn coil on a diameter of $7 \mathrm{~cm}$ annealed at $850^{\circ} \mathrm{C}$ for about $17 \mathrm{~h}$. Fig. 2 also has the temperature history for comparison. At temperatures between 500 and $600{ }^{\circ} \mathrm{C}$ the polymer jacket burns into a carbon ash. As the jacket swells on burning, it stresses the wound fiber coil, generating temporary microbending losses. If the coil is wound with too much tension the fiber will break during this portion of the annealing cycle. As the jacket burns into ash the stress is relieved and the transmittance returns to near preannealing conditions. Thus, micro-bending loss is not a dominate factor in this fiber. (Further visual inspection of the fiber surface after annealing shows only minor flaws.) However, as the fiber temperature reaches $800{ }^{\circ} \mathrm{C}$ the transmittance drops by about $7 \%$. All annealed coils show some drop in transmittance as the temperature reaches $800{ }^{\circ} \mathrm{C}$. Fig. 3 shows increased optical loss, in $\mathrm{dB} / \mathrm{km}$, due to annealing for this fiber type versus annealing time at $850{ }^{\circ} \mathrm{C}$. The loss increases linearly with annealing time at a rate of about $0.41 \pm 0.05 \mathrm{~dB} /(\mathrm{km} \bullet \mathrm{h})$. 


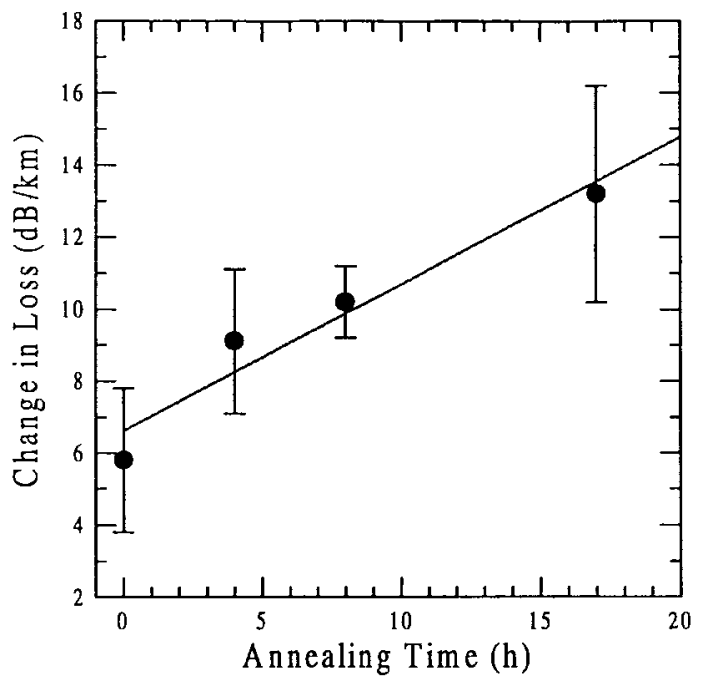

Fig. 3. Annealing-induced loss for 100.9 turn, $7 \mathrm{~cm}$ diameter coils annealed at $850{ }^{\circ} \mathrm{C}$ for $0.1,4,8$, and $17 \mathrm{~h}$.

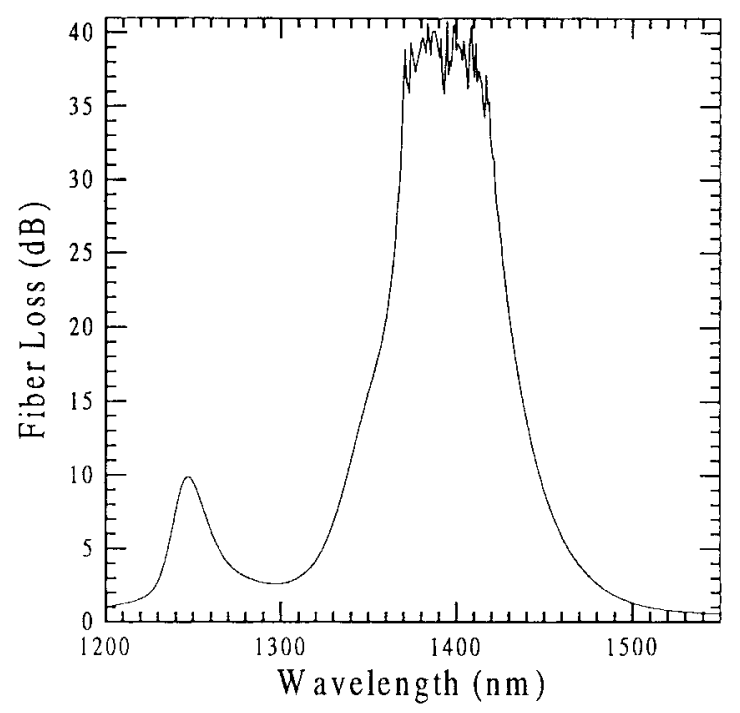

Fig. 4. Spectral loss of a 100.9 turn, $7 \mathrm{~cm}$ diameter coil annealed at $906^{\circ} \mathrm{C}$ for over $100 \mathrm{~h}$

Annealing significantly increases the loss in this fiber from $0.34 \mathrm{~dB} / \mathrm{km}$ to about $9 \mathrm{~dB} / \mathrm{km}$ for modest annealing times.

The loss in these annealed fibers at $1300 \mathrm{~nm}$ can also be attributed to $\mathrm{OH}$ absorption. $\mathrm{OH}$ enters the fiber through a reaction with water from the air and hydrogen in the glass [34]-[37]. For annealed fiber, in an air atmosphere, the main reaction is with water. (The hydrogen concentration in this fiber is assumed low at high temperatures.) The glass-water reaction has been established as: $\left(\mathrm{H}_{2} \mathrm{O}\right)_{\text {vapor }}+$ $(\equiv \mathrm{Si}-\mathrm{O}-\mathrm{Si} \equiv)_{\text {glass }} \rightarrow 2(\equiv \mathrm{Si}-\mathrm{OH})_{\text {glass }}[34]$. The spectral loss of our fiber has been measured over the 1200-1550 nm range, and an increased absorption due to $\mathrm{OH}$ is measurable after annealing for $17 \mathrm{~h}$. The loss at our laser wavelength, 1287 $\mathrm{nm}$, is about $6 \mathrm{~dB} / \mathrm{km}$ for a $17 \mathrm{~h}$ annealing and about half the measured loss in Fig. 3 for the same annealing time. To show $\mathrm{OH}$ absorption in an annealed fiber a coil about $20 \mathrm{~m}$ in length was heated for more than $100 \mathrm{~h}$ at $906{ }^{\circ} \mathrm{C}$. The strong absorption spectra is shown in Fig. 4.

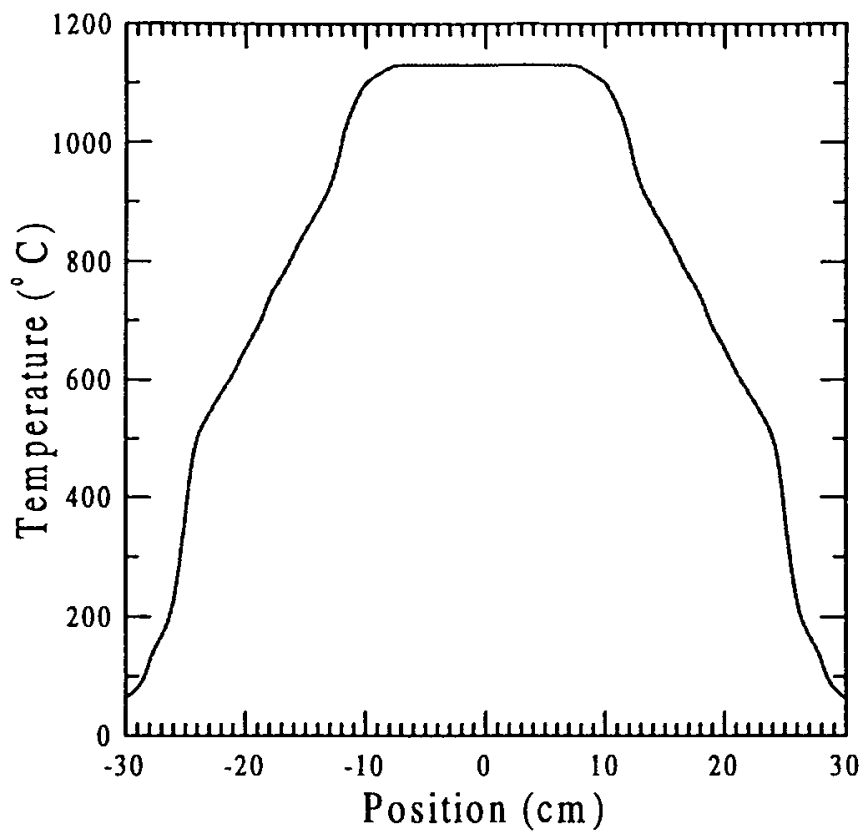

Fig. 5. Temperature profile of the tube furnace used for high temperature annealing.

The loss in fibers annealed at $850{ }^{\circ} \mathrm{C}$ appears to be dominated by $\mathrm{OH}$ absorption in the 1200 to $1500 \mathrm{~nm}$ wavelength region for annealing times greater than $10 \mathrm{~h}$. At shorter times the $\mathrm{OH}$ loss is too small to measure with confidence. However, the loss due to scattering cannot be discounted because the coils radiate enough light to be viewed with an infrared viewer and localized radiation points can be seen in the fiber. At short annealing times, less than $10 \mathrm{~h}$ at $850{ }^{\circ} \mathrm{C}$, the largest part of the optical loss appears to come from scattering. Microbending loss does not appear to significantly contribute to the loss of this fiber after the jacket is burned away, as seen in Fig. 2.

\section{B. Optical Fiber Crystallization}

To explore the devitrification of annealed fibers further, a high temperature tube furnace was constructed to anneal at temperatures from 850 to $1300{ }^{\circ} \mathrm{C}$. To match the previous annealing cycle, the heating rate of the oven was set to $5{ }^{\circ} \mathrm{C} / \mathrm{min}$. The cooling rate was increased to $20^{\circ} \mathrm{C} / \mathrm{min}$, to decrease the cycle time to about $16 \mathrm{~h}$. Fig. 5 shows a typical temperature profile of the oven with a hot zone of about 19 $\mathrm{cm}$. A fused quartz tube about $60 \mathrm{~cm}$ long with a $7 \mathrm{~mm}$ I.D. was used to anneal fibers at high temperatures. Fused quartz rings were used to suspend the fiber in the tube to avoid any anomalous diffusion between the tube and fiber at the higher temperatures. After each annealing cycle the fiber was examined and photographed under a microscope. The optical spectra of these fibers was taken to measure any $\mathrm{OH}$ absorption loss, however, no loss could be measured for the short annealing time used.

Figs. 6, 7, 9, and 11 show photographs of the surface of a fiber for annealing temperatures from 850 to about $1300{ }^{\circ} \mathrm{C}$ for 8 h. Fig. 6 shows a fiber annealed at $850^{\circ} \mathrm{C}$ to compare with the annealed fiber coils discussed above. Only minor surface defects are present. (Care was used in handling the fiber to 


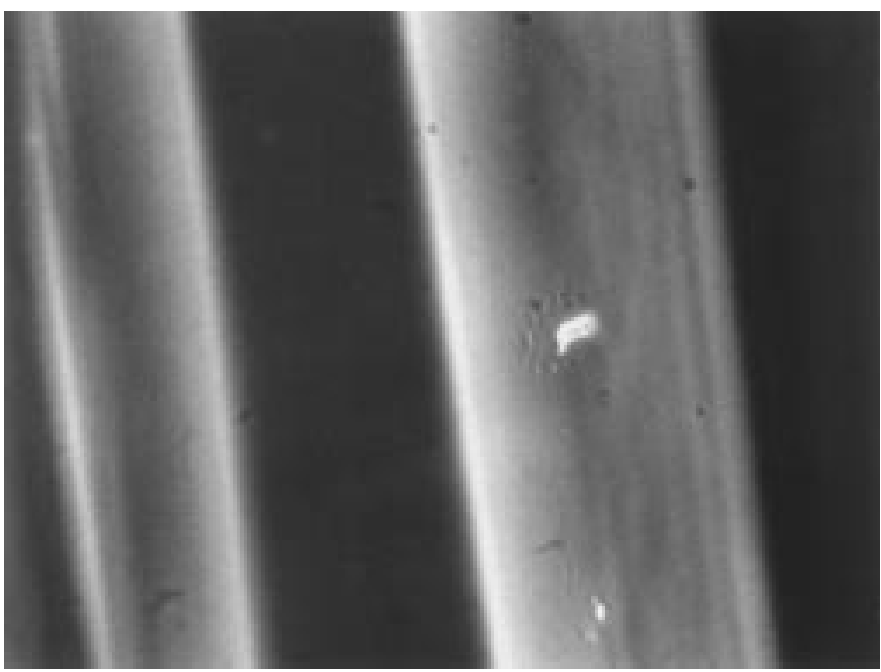

Fig. 6. $125-\mu \mathrm{m}$ fiber annealed at about $850{ }^{\circ} \mathrm{C}$ for $8 \mathrm{~h}$.

avoid scratching or other damage before photographing.) With further mechanical and environmental exposure, the formation shown in the figure will ultimately lead to a crack propagating into the fiber. However, with proper packaging, the fiber annealed at $850{ }^{\circ} \mathrm{C}$ can be preserved through many thermal cycles $\left(-65\right.$ to $\left.+125^{\circ} \mathrm{C}\right)$ and vibration (greater than $20 \mathrm{~g}$ or greater than $196 \mathrm{~m} / \mathrm{s}^{2}$ ) [38].

Fig. 7 shows a photograph of the surface of a fiber annealed at about $1100{ }^{\circ} \mathrm{C}$. The surface of the glass is beginning to undergo a phase change as microcrystals cover significant portions of the surface. Fig. 8 shows the transmittance of the fiber and thermal history of the annealing cycle for the fiber shown in Fig. 7. The fiber transmittance falls with time as the fiber is held at about $1100{ }^{\circ} \mathrm{C}$. This loss in transmittance can be attributed to the devitrification of the core glass, scattering light out of the fiber and possibly due to stress-induced loss from the crystal growth on the surface. (The spectra of fiber annealed at about 1040 and $1220{ }^{\circ} \mathrm{C}$ for $8 \mathrm{~h}$ showed no measurable increase in $\mathrm{OH}$ absorption.) When the oven starts to cool rapidly, the transmittance registers the thermal shock. This fiber's transmittance recovers to near its value before cooling. In other tests, the transmittance has been both lower and higher after the fiber cools. A fiber with this surface is slightly weaker than the fiber annealed at $850{ }^{\circ} \mathrm{C}$ due to surface defects.

Fig. 9 shows a photograph of the surface of a fiber annealed at about $1220^{\circ} \mathrm{C}$. The fiber surface after annealing is fracturing as polycrystalline structures form. Fig. 10 shows the transmittance and thermal history of the annealing cycle. Again, the fiber transmittance falls with time as the fiber is held at about $1220^{\circ} \mathrm{C}$. As the oven cools rapidly, the different thermal expansions of polycrystalline cristobalite and glass may further fracture the fiber and increase the stress-induced loss to reduce the fiber transmittance [39]. This fiber is fragile and difficult to handle without breaking. Under mechanical movement the surface cracks quickly propagate through the fiber. The birefringence of fiber heated above $1220{ }^{\circ} \mathrm{C}$ increases due to waveguide deformation [27]. However, this would not contribute to a measurable loss in the short length of fiber used here.

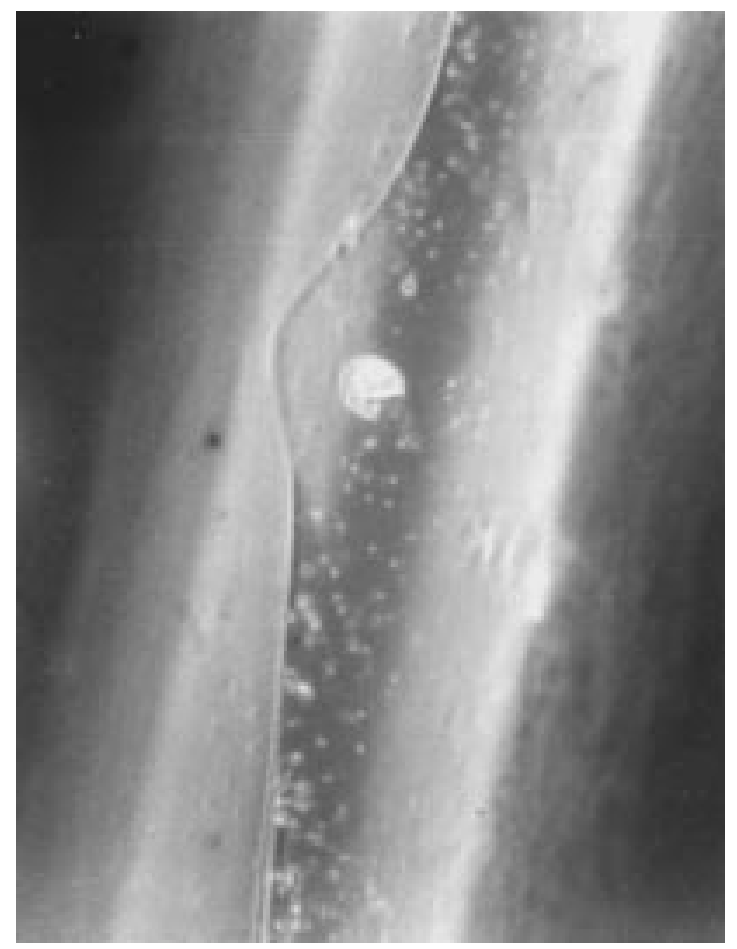

Fig. 7. $125-\mu \mathrm{m}$ fiber annealed at about $1100{ }^{\circ} \mathrm{C}$ for $8 \mathrm{~h}$.

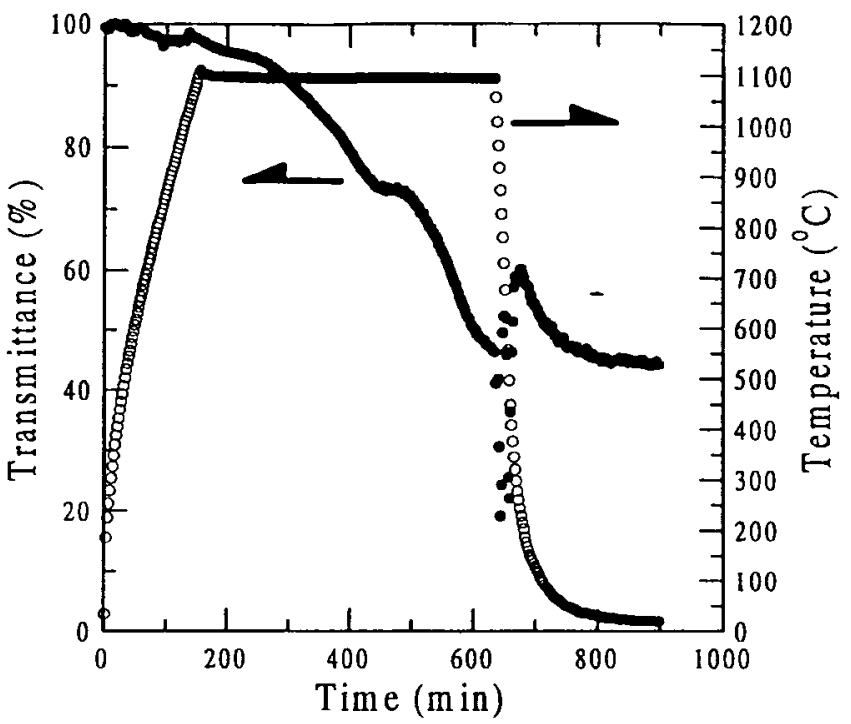

Fig. 8. The transmittance and thermal history of a fiber annealed at about $1100{ }^{\circ} \mathrm{C}$ for $8 \mathrm{~h}$. The $\mathrm{o}$ 's mark the temperature and the $\bullet$ 's mark the transmittance.

Fig. 11 shows a photograph of the surface of a fiber annealed at about $1310{ }^{\circ} \mathrm{C}$. The fiber surface after annealing is completely fractured by polycrystalline structures. Fig. 12 shows the transmittance and thermal history of the fiber during the annealing. As the temperature approaches $1300{ }^{\circ} \mathrm{C}$ the fiber no longer transmits. This is attributed to the nearly complete devitrification of the glass fiber, which breaks as a crystal fracture plane propagates through the fiber. Again, this fiber is extremely fragile. The fiber is no longer translucent and has a white appearance under normal laboratory lighting. 


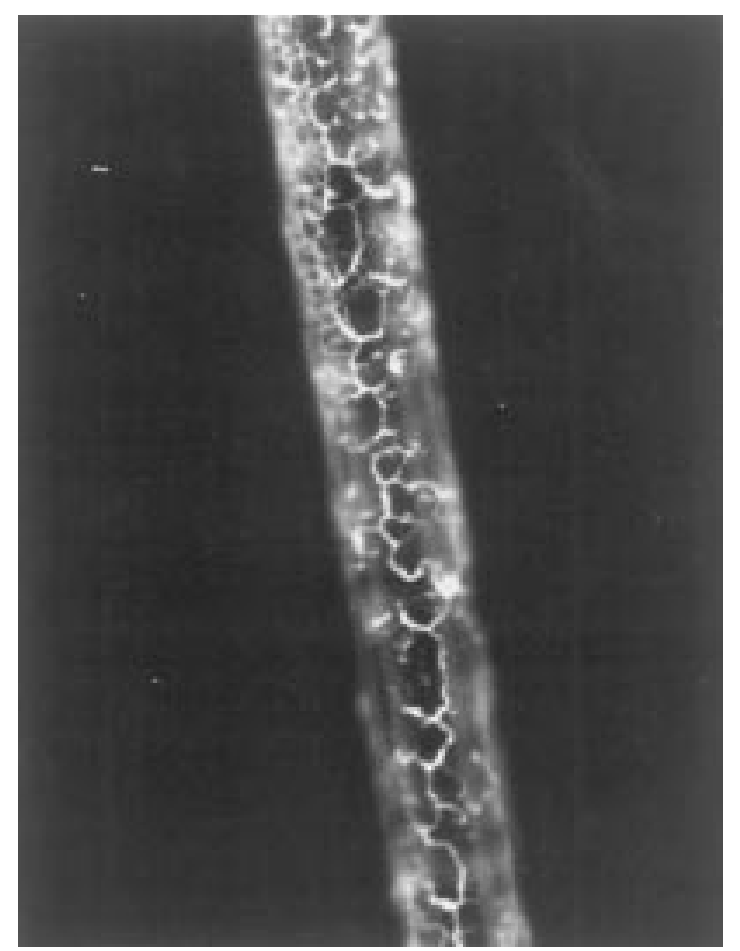

Fig. 9. $125 \mu \mathrm{m}$ fiber annealed at about $1220^{\circ} \mathrm{C}$ for $8 \mathrm{~h}$.

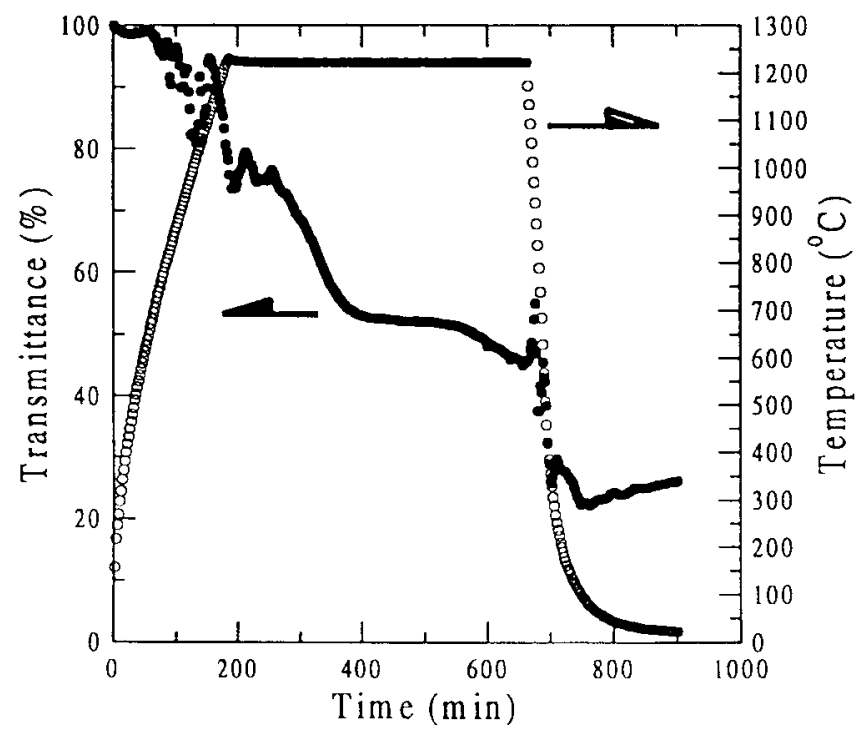

Fig. 10. The transmittance and thermal history of a fiber annealed at about $1220{ }^{\circ} \mathrm{C}$ for $8 \mathrm{~h}$. The o's mark the temperature and the $\bullet$ 's mark the transmittance.

Fig. 13 shows the transmittance change for many fibers annealed $8 \mathrm{~h}$ at temperatures from 850 to about $1300{ }^{\circ} \mathrm{C}$. At annealing temperatures above $1000{ }^{\circ} \mathrm{C}$, the loss due to devitrification significantly increases. This may be due to the temperature reaching the crystallization activation energy of the glass [10], [20]. The linear and spline fits are presented in Fig. 13 to aid in seeing the transition around $1000{ }^{\circ} \mathrm{C}$ and to note that the transmittance change in the fiber is linear with increasing temperature above $1000{ }^{\circ} \mathrm{C}$. At these short annealing times $\mathrm{OH}$ absorption does not measurably contribute to the fiber's optical loss.

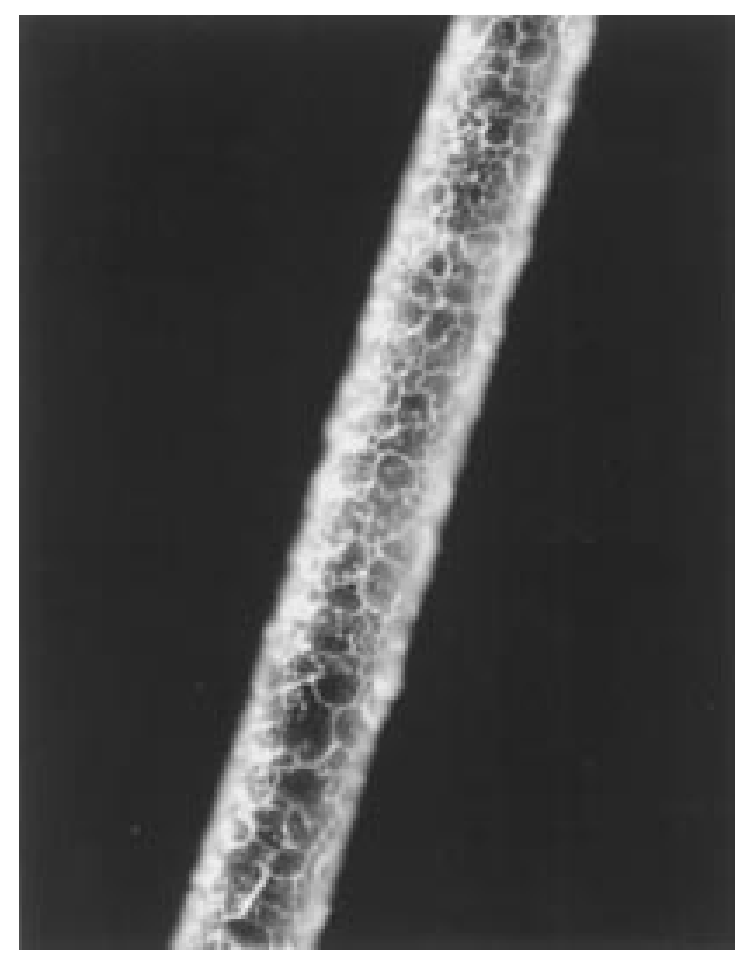

Fig. 11. $125 \mu \mathrm{m}$ fiber annealed at about $1310^{\circ} \mathrm{C}$ for $8 \mathrm{~h}$.

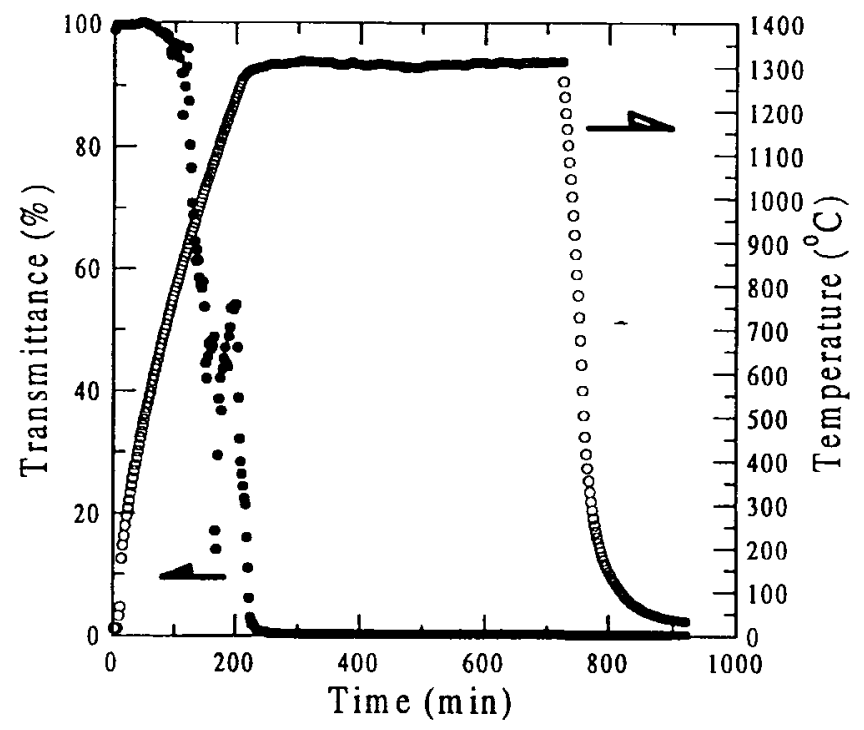

Fig. 12. The transmittance and thermal history of a fiber annealed at about $1310{ }^{\circ} \mathrm{C}$ for $8 \mathrm{~h}$. The $\mathrm{o}^{\prime} \mathrm{s}$ mark the temperature and the $\bullet$ 's mark the transmittance.

\section{Summary AND CONCLUSIONS}

The current sensitivity and optical loss of annealed fiber coils are linearly dependent on the time of annealing at $850^{\circ} \mathrm{C}$. For optical fiber current sensing the most important fiber parameter is the elimination of linear birefringence [4], [23], [24]. Depolarization from scattering is a secondary consideration for optimum current sensitivity [25]. The optical loss in a fiber current sensor has much greater bounds than depolarization and linear birefringence. Many fiber current sensors can have up to $10 \mathrm{~dB}$ of loss before optical power budgets and photodetector noise limit performance. Therefore, 


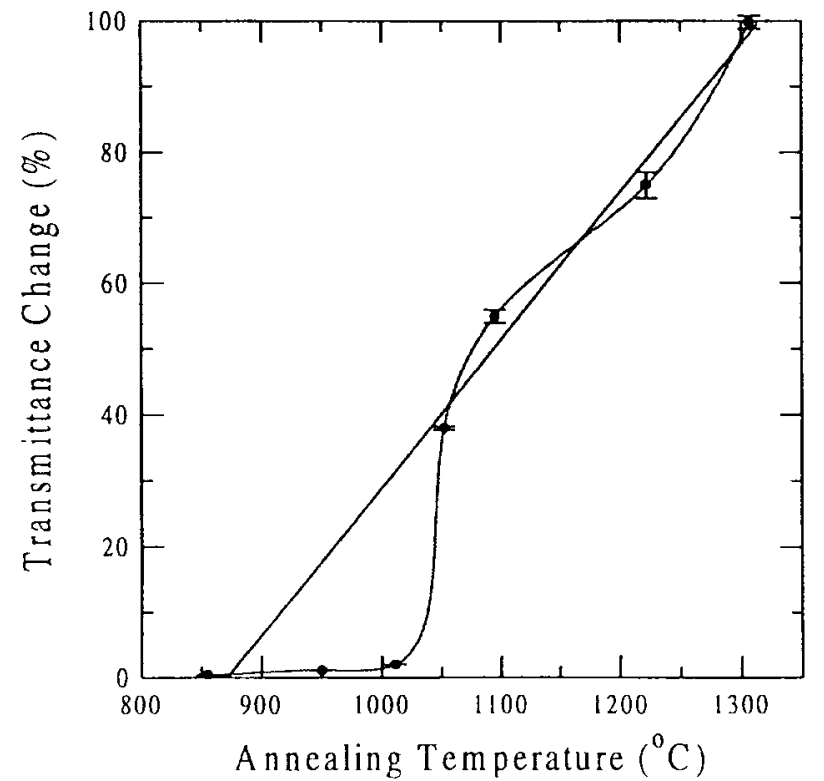

Fig. 13. The transmittance change for fibers annealed $8 \mathrm{~h}$ at different temperatures.

when optical fiber is annealed, the maximum temperature and time must be tailored to remove all linear birefringence and avoid significant depolarization. As discussed devitrification appears to effect a current sensor's response primarily from depolarization effects.

The loss in annealed fibers at $1300 \mathrm{~nm}$ has possibly three causes, scattering, absorption, and stress-induced. Scattering comes from the index difference between a crystal site and the vitreous glass. Absorption in the 1200 to $1500 \mathrm{~nm}$ range comes from $\mathrm{OH}$. The stress-induced losses can arise when the surface of the fiber is severely damaged by crystal growth. At annealing temperatures, around $850{ }^{\circ} \mathrm{C}$, the optical loss of the fiber is due to both $\mathrm{OH}$ absorption and scattering. Stressinduced loss is not considered a major source, because the surface is still visibly well preserved. $\mathrm{OH}$ and scattering loss is small, about $0.2 \mathrm{~dB}$ for a $20 \mathrm{~m}$ coil annealed at $850^{\circ} \mathrm{C}$ for $4 \mathrm{~h}$. For longer annealing times the optical loss is dominated by $\mathrm{OH}$ absorption.

For higher annealing temperatures above $1000{ }^{\circ} \mathrm{C}$ and times less than $10 \mathrm{~h}$, the loss in the fiber is due to scattering, fiber fracture, and possibly stress-induced loss from surface crystal growth. At these high temperatures the optical loss and fiber fragility increase, making current sensing with this type of fiber impractical. Annealing at temperatures above $1000{ }^{\circ} \mathrm{C}$ promotes crystal growth starting primarily at the surface and propagating into the fiber to the core. This result agrees with the comments of Matusita and Sakka that nucleation and crystal growth will propagate from the surface inward for heating rates greater than $2{ }^{\circ} \mathrm{C} / \mathrm{min}$ (Our heating rate was $5{ }^{\circ} \mathrm{C} / \mathrm{min}$.) [21].

Crystal growth at the surface is greatly affected by the treatment and type of jacket on the annealed fiber. As the jacket burns, the surface of the glass is altered to promote crystal growth through chemical attack [16]. Any residue left on the surface will also serve as nucleation sites, accelerating devitrification. Therefore, for fiber that endures fire or other high-temperature processing, the jacket material becomes critical to the fiber survivability and loss. From the data presented here, sensors that use silica fiber above $1000{ }^{\circ} \mathrm{C}$ are not practical for long term use.

The effects of optical fiber devitrification will limit the performance and lifetime of silica fiber sensors that operate at temperatures above $800{ }^{\circ} \mathrm{C}$. Even at relatively low temperatures, $\mathrm{OH}$ absorption in the 1200-1500 nm wavelength band will alter the calibration of intensity-based sensors.

The method of monitoring the transmittance of the fiber during heat treatment could complement other methods of monitoring crystal growth in optical fiber for annealing times less than $10 \mathrm{~h}$ [10]. For annealing times greater than $10 \mathrm{~h}$ the loss measurement will be complicated by $\mathrm{OH}$ absorption in the 1200 to $1500 \mathrm{~nm}$ range. Longer annealing times could be used if wavelengths outside of the $\mathrm{OH}$ absorption bands were used.

For Verdet constant determinations in annealed optical fiber, the effects of depolarization must be considered as it directly effects the measured Faraday rotation. Also, Verdet constant measurements in the $1200-1500 \mathrm{~nm}$ region require annealing times less than $10 \mathrm{~h}$, because $\mathrm{OH}$ absorption changes the dispersion of the fiber. (The Verdet constant in diamagnetic materials is directly proportional to $d n / d \lambda$ [26].)

\section{ACKNOWLEDGMENT}

The author would like to thank S. M. Etzel for preparing many of the fiber coils for annealing and P. A. Williams for assisting in the PMD measurement.

\section{REFERENCES}

[1] K. Shiraishi, Y. Aizawa, and S. Kawakami, "Beam Expanding Fiber Using Thermal Diffusion of the Dopant," J. Lightwave Technol., vol. 8, pp. 1151-1161, Aug. 1990.

[2] H. Kuwahara, M. Sasaki, and N. Tokoyo, "Efficient coupling from semiconductor lasers into single-mode fibers with tapered hemispherical ends," Appl. Opt., vol. 19, pp. 2578-2583, Aug. 1980.

[3] S. Okude, T. Sakai, A. Wada, R. Yamauchi, "Novel chirped fiber grating utilizing a thermally diffused taper-core fiber," in OFC'96 Tech. Dig., TuO7, Feb. 1996, pp. 88-89.

[4] D. Tang, A. H. Rose, G. W. Day, and S. M. Etzel, "Annealing of linear birefringence in single mode fiber coils: Application to optical fiber current sensors," J. Lightwave Technol., vol. 9, pp. 1031-1037, Aug. 1991.

[5] X.-C. Long, R. A. Myers, and S. R. J. Brueck, "A Poled Electrooptic Fiber,” IEEE Photon. Technol. Lett., vol. 8, pp. 227-229, Feb. 1996.

[6] R. J. Campbell and R. Kashyap, "The properties and applications of photosensitive germanosilicate fiber," Int. J. Optoelectron., vol. 9, pp. 33-57, Jan. 1994.

[7] D. S. Shenk and L. G. Cohen, "Fiber-optic tapping via induced scattering," J. Lightwave Technol., vol. 7, pp. 1556-1558, Oct. 1989.

[8] G. O. Jones, Glass. New York: Wiley, 1956, pp. 1-44.

[9] D. R. MacFarlane and M. Fragoulis, "Theory of devitrification in multicomponent glass forming systems under diffusion control," Phys. Chem. Glasses, vol. 27, pp. 228-234, Dec. 1986.

[10] Treatise on Materials Science and Technology, Vol. 17: Glass II, M. Tomozawa and R. H. Doremus, Eds. New York: Academic, 1979, pp. 41-113.

[11] W. Vogel, Glass Chemistry. Berlin, Germany: Springer-Verlag, 1994, pp. 290-295.

[12] U. C. Paek and C. R. Kurkjian, "Calculation cooling rate and induced stresses in drawing of optical fibers," J. Amer. Cer. Soc., vol. 58, pp. 330-335, 1975.

[13] J.-H. Jean and T. K. Gupta, "Kinetics of cristobalite formation in binary borosilicate-high silica glass composite," in Ceramic Transactions, Vol. 30: Nucleation and Crystallization in Liquids and Glasses, M. C. Weinberg, Ed. Westerville: The American Ceramic Society, 1993, pp. 347-354. 
[14] V. A. Shneidman, "Time-dependent nucleation during reheating of a rapidly quenched glass," J. Chem. Phys., vol. 102, pp. 1791-1795, Jan. 1995.

[15] J.-H. Jean and T. K. Gupta, "Devitrification inhibitors in borosilicate glass and binary borosilicate glass composite," J. Mater. Res., vol. 10, pp. 1312-1320, May 1995.

[16] E. D. Zanotto, "Experimental studies of surface nucleation and crystallization of glasses," in Ceramic Transactions, Vol. 30: Nucleation and Crystallization in Liquids and Glasses, M. C. Weinberg, Ed. Westerville: The American Ceramic Society, 1993, pp. 65-74.

[17] P. C. P. Bouten and G. de With, "Crack nucleation at the surface of stressed fibers," J. Appl. Phys., vol. 64, pp. 3890-3900, Oct. 1988.

[18] H. Duken, "Surface chemistry of optical glasses," J. Non-Crystalline Sol., vol. 129, pp. 64-75, Jan. 1991.

[19] P. J. N. Renders, C. H. Gammons, and H. L. Barnes, "Precipitation and dissolution rate constants for cristobalite from 150 to $300{ }^{\circ} \mathrm{C}$," Geochimica et Cosmochimica Acta, vol. 59, pp. 77-85, Jan. 1995.

[20] D. R. MacFarlane, M. Matecki, and M. Poulain, "Crystallization in fluoride glasses, I. Devitrification on reheating," J. Non-Crystalline Sol., vol. 64, pp. 351-362, 1984.

[21] K. Matusita and S. Sakka, "Kinetic study of the crystallization of glass by differential scanning calorimetry," Phys. Chem. Glasses, vol. 20, pp. 81-84, Aug. 1979

[22] E. A. Marseglia, "Kinetic Theory of Crystallization of Amorphous Materials," J. Non-Crystalline Sol., vol. 41, pp. 31-36, Jan. 1980.

[23] A. H. Rose, Z. B. Ren, and G. W. Day, "Improved annealing technique for optical fiber," in Proc. SPIE, vol. 2360, Oct. 1994, pp. 306-311.

[24] "Twisting and annealing optical fiber for current sensors," $J$. Lightwave Technol., vol. 14, pp. 2492-2498, Nov. 1996.

[25] M. N. Deeter and P. A. Williams, "Magneto-optic characterization of iron garnet crystals using photoelastic modulation," IEEE Trans. Magnet., vol. 28, pp. 3234-3236, Sept. 1992.

[26] M. N. Deeter, G. W. Day, and A. H. Rose, "Section 9, magnetooptic materials, 9.1 crystals and glasses," in Handbook of Laser Science and Technology, Supplement 2: Optical Materials, M. J. Weber, Ed. Boca Raton, FL, CRC Press, Inc., 1995, pp. 367-402.

[27] J. Stone, "Stress-optic effects, birefringence, and reduction of birefringence by annealing in fiber Fabry-Perot interferometers," J. Lightwave Technol., vol. 6, pp. 1245-1248, July 1988.
[28] S. C. Rashleigh and R. Ulrich, "Magneto-optic current sensing with birefringent fibers," Appl. Phys. Lett., vol. 34, pp. 768-770, June 1979.

[29] C. D. Poole, "Measurement of polarization-mode dispersion in singlemode fibers with random mode coupling," Opt. Lett., vol. 14, pp. 523-525, May 1989.

[30] J. Kirchhof, S. Unger, V. Reichel, A. Schwuchow, "Background loss and devitrification in Nd-doped fiber laser glass," OFC 96 Techn. Dig., TuL4, Feb. 1996, pp. 60-61.

[31] V. McGahay and M. Tomozawa, "Phase separation in rare-earth-doped $\mathrm{SiO}_{2}$ glasses," J. Non-Crystalline Sol., vol. 159, pp. 246-252, 1993.

[32] H. Hattori, S. Sakaguchi, T. Kanamori, and Y. Terunuma, "Scattering characteristics of crystallites in fluoride optical fibers," Appl. Opt., vol. 26, pp. 2683-2687, July 1987.

[33] S. Sakaguchi, "Evaluation of extrinsic scattering loss due to crystallization in fluoride optical fibers," J. Lightwave Technol., vol. 11, pp 187-191, Feb. 1993.

[34] T. Bell, G. Hetherington, and K. H. Jack, "Water in vitreous silica, Pt. 2: Some aspects of hydrogen-water equilibria," Phys. Chem. Glasses, vol. 3, pp. 141-146, Oct. 1962.

[35] A. Iino, M. Kuwabara, and K. Kokura, "Mechanisms of hydrogeninduced losses in silica-based optical fibers," J. Lightwave Technol., vol. 8, pp. 1675-1679, Nov. 1990.

[36] T. Shiota, H. Kidaka, O. Fukuda, and K. Inada, "High-temperature effects of aluminum-coated fiber," J. Lightwave Technol., vol. LT-4, pp. 1151-1155, Aug. 1986.

[37] N. Uesugi, T. Kuwabara, Y. Ishida, K. Noguchi, Y. Negishi, and N. Uchida, "Infrared loss increase phenomenon of coated optical fibers at high-temperatures," J. Lightwave Technol., vol. LT-3, pp. 824-828, Aug. 1985.

[38] R. L. Patterson, A. H. Rose, D. Tang, and G. W. Day, "A fiber-optic current sensor for aerospace applications," IEEE Aerospace Electron. Syst. Mag., vol. 5, pp. 10-14, Dec. 1990.

[39] I. P. Swainson and M. T. Dove, "On the thermal expansion of $\beta$ cristobalite," Phys. Chem. Minerals, vol. 22, pp. 61-65, Jan. 1995.

A. H. Rose, for a biography, see this issue, p. 807. 